\title{
A Rare Case of Primary Myelofibrosis With a Solitary 1q Triplication
}

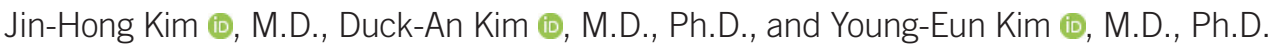 \\ Department of Laboratory Medicine, Hanyang University Seoul Hospital, Hanyang University College of Medicine, Seoul, Korea
}

\section{Dear Editor,}

Triplication of the long arm of chromosome 1 is a rare chromosomal abnormality reported in hematologic malignancies such as acute myeloid leukemia (AML), acute lymphoblastic leukemia, myelodysplastic syndrome (MDS), lymphoma, myeloproliferative neoplasm (MPN), multiple myeloma, and Fanconi anemia (FA) [1, 2]. Among these, only one case of primary myelofibrosis (PMF) has revealed 1q triplication in bone marrow karyotyping. Furthermore, 1q triplication as a sole cytogenetic abnormality is extremely rare, with only four cases identified in patients with AML, MDS, FA, or PMF [1-3]. We report the first case of solitary $1 q$ triplication in a patient with PMF without other hematologic malignancies. This study was approved by the Institutional Review Board of Hanyang University Medical Center, Seoul, Korea (HYUH 2019-09-009).

A 38-year-old female patient was admitted to the pulmonology department of Hanyang University Seoul hospital, Seoul, Korea, with chronic cough and was diagnosed as having miliary tuberculosis in May 2017. Bicytopenia was found at admission, and she was transferred to the hemato-oncology department for fur- ther evaluation. Informed consent was obtained from the patient before bone marrow study and genetic testing.

Her complete blood count (CBC) revealed a white blood cell count of $1.7 \times 10 \% / \mathrm{L}$ (segmented neutrophils, $50 \%$; band form neutrophils, $2 \%$; lymphocytes, $44 \%$; monocytes, $3 \%$; and eosinophils, $1 \%$ ), an $\mathrm{Hb}$ level of $62 \mathrm{~g} / \mathrm{L}$, and a platelet count of $272 \times 10^{9} / \mathrm{L}$. The initial mean corpuscular volume was decreased to $65.8 \mathrm{fL}$. A peripheral blood smear showed poikilocytosis with teardrop-shaped red blood cells (Fig. 1A). An abdominal computed tomography showed mild hepatosplenomegaly, and serum lactate dehydrogenase level was elevated to $5.3 \mu \mathrm{kat} / \mathrm{L}$ (reference range: $2.3-4.5 \mu \mathrm{kat} / \mathrm{L})$.

The initial bone marrow biopsy done in May 2017 revealed inadequate aspirate due to dry tap. The core biopsy showed normal cellularity $(50 \%)$ with megakaryocytic hyperplasia and atypia. The megakaryocytes were increased in number and formed small to large clusters with anisocytosis. Osteosclerosis was not significant (Fig. 1B). Grade MF-2 bone marrow fibrosis was identified by reticulin stain (Fig. 1C), and grade 1 collagen deposition was detected by Masson's trichrome stain. Neither
Received: May 7, 2019

Revision received: July 2, 2019

Accepted: September 23, 2019

Corresponding author: Duck-An Kim, M.D., Ph.D.

Department of Laboratory Medicine, Hanyang University Seoul Hospital, Hanyang University College of Medicine, 222-1 Wangsimni-ro, Seongdonggu, Seoul 04763, Korea

Tel: +82-2-2290-8977, Fax: +82-2-2290-9193

E-mail: dukim@hanyang.ac.kr

Co-corresponding author: Young-Eun Kim, M.D., Ph.D.

Department of Laboratory Medicine, Hanyang University Seoul Hospital, Hanyang University College of Medicine, 222-1 Wangsimni-ro, Seongdonggu, Seoul 04763, Korea

Tel: +82-2-2290-8974, Fax: +82-2-2290-9193

E-mail: young0eun@hanyang.ac.kr

\section{(c) (1) (8)}

(C) Korean Society for Laboratory Medicine

This is an Open Access article distributed under the terms of the Creative Commons Attribution Non-Commercial License (http://creativecommons.org/licenses/by-nc/4.0) which permits unrestricted non-commercial use, distribution, and reproduction in any medium, provided the original work is properly cited. 

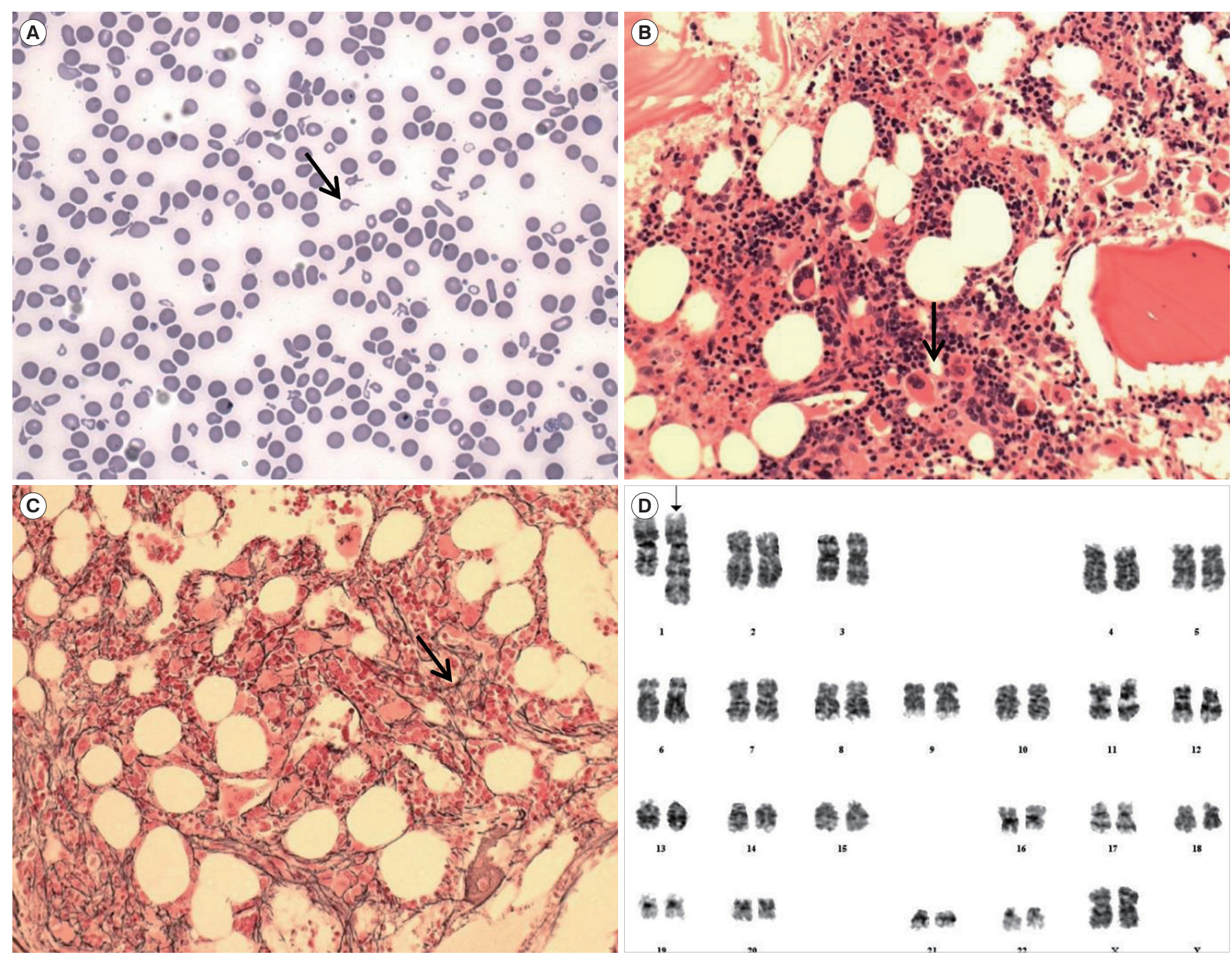

Fig. 1. Peripheral blood, bone marrow, and karyotypic findings of the patient. (A) Peripheral blood smear showing teardrop-shaped cells (arrow) and anisocytosis (Wright-Giemsa stain, $\times 400$ ). (B) Bone marrow biopsy demonstrating proliferative and clustered megakaryocytes with atypia (arrow) (H\&E stain, $\times 200$ ). (C) Grade MF-2 reticulin fibrosis (arrow) (reticulin stain, $\times 400$ ). (D) Karyotyping showing 46,XX,trp(1)(q21q32) (arrow).

Abbreviations: H\&E, Hematoxylin and Eosin; MF, myelofibrosis.

necrosis nor granuloma was observed in the bone marrow. Chromosome testing showed solitary trp(1)(q21q32) in all 20 metaphase cells (Fig. 1D). JAK2-V617F, CALR, and MPL mutations were all tested negative. In addition, no other pathogenic variant was identified in the AML gene panel testing including 45 genes such as ASXL1, EZH2, TET2, IDH1, IDH2, SRSF2, and SF3B1. Acid-fast bacilli staining and tuberculosis culture of bone marrow samples were negative. The patient was diagnosed as having PMF based on the 2016 revision of the WHO classification [4].

Following anti-tuberculosis therapy with oral isoniazid, rifampicin, ethambutol, and pyridoxine, the miliary tuberculosis im- proved. However, the bicytopenia persisted for eight months after treatment; the follow-up (21 months after the first evaluation) bone marrow study and chromosome test results were the same as the previous ones.

Of the previous two cases of $1 q$ triplication in MPN patients, one was reported during the follow-up of chronic myeloid leukemia (CML), and the other case was detected as the sole cytogenetic abnormality in a PMF patient with a BCR/ABL1 negative state following CML treatment [2]; in this case, unlike the previous reports, 1q triplication was reported in a PMF patient without evidence of other hematologic malignancies (Table 1).

Approximately $12 \%$ of patients with PMF have been reported 
Table 1. Summary of 1q triplication in patients with MPN

\begin{tabular}{lccccc}
\hline $\begin{array}{l}\text { Patient, age } \\
\text { (yr)/sex }\end{array}$ & Diagnosis & Triplication region & $\begin{array}{c}\text { Additional chromosomal } \\
\text { abnormalities }\end{array}$ & $\begin{array}{c}\text { Presence of another clonal } \\
\text { marker }\end{array}$ & Reference \\
\hline 38/F & PMF & $\operatorname{trp}(1)($ q21q32) in all 20 metaphase cells & None & None (by AML gene panel test) & Present study \\
28/M & CML (follow-up period) & $\operatorname{trp}(1)(q 24 q 41)$ in all 20 metaphase cells & $\begin{array}{c}\mathrm{t}(9 ; 22)(q 34 ; q 11.2) \text { in all 20 } \\
\text { metaphase cells analyzed }\end{array}$ & NA & Park, et al. [2] \\
57/F & CML $\rightarrow$ PMF & $\operatorname{trp}(1)(q 21 q 32)$ in 6/22 metaphase cells & None & NA & Park, et al. [2] \\
\hline
\end{tabular}

Abbreviations: MPN, myeloproliferative neoplasm; F, female; M, male; PMF, primary myelofibrosis; AML, acute myeloid leukemia; CML, chronic myeloid leukemia; NA, not available.

as triple-negative for JAK2-V617F, CALR, and MPL mutations [4]. In these cases, searching for frequent accompanying mutations is helpful in determining the clonality of the disease $[4,5]$. In our case, no mutation was found in the AML gene panel test; thus, the only evidence of clonality was $1 \mathrm{q}$ triplication.

As previously established, 1q duplication is one of the most common abnormalities in PMF [5-7]. In addition, 33\% of the reported $1 q$ triplication cases (11/33) and $60 \%$ of the solitary 1q triplication cases (3/5), including the present study, share a triplicated region on 1q21 to 1q32 [1-3]. Thus, there might be a correlation between the 1q21 to $1 q 32$ region and the pathogenesis of hematologic malignancies.

In conclusion, this is the first case of sole1q triplication in a patient with PMF without other hematologic malignancies. Further study is needed to confirm the pathogenesis of $1 \mathrm{q}$ triplication in the myeloproliferative process.

\section{Author Contributions}

Jin-Hong Kim designed the study, interpreted genetic data, analyzed clinical information, and wrote the article. Duck-An Kim and Young-Eun Kim supervised all processes of the research and revised the article.

\section{Conflicts of Interest}

None declared.

\section{Research Funding}

This work was supported by the research fund of Hanyang University (HY-2019).

\section{ORCID}

Jin-Hong Kim https://orcid.org/0000-0002-5369-0725

Duck-An Kim https://orcid.org/0000-0001-7280-1227

Young-Eun Kim https://orcid.org/0000-0002-4082-7630

\section{REFERENCES}

1. Park TS, Lee ST, Song J, Lee KA, Kim J, Kim SJ, et al. A tandem triplication, $\operatorname{trp}(1)(q 21 q 32)$, in a patient with follicular lymphoma: a case study and review of the literature. Cancer Genet Cytogenet 2009;189: 127-31.

2. Park TS, Lee SG, Cheong JW, Song J, Lee KA, Kim J, et al. Two case reports of $1 q$ triplication in myeloproliferative neoplasms. Cancer Genet Cytogenet 2009;191:111-2.

3. Ha JS and Choi MS. 1q triplication as sole cytogenetic abnormality in myelodysplastic syndrome. Leuk Lymphoma 2011;52:1387-9.

4. Swerdlow SH, Campo E, et al. eds. WHO classification of tumours of haematopoietic and lymphoid tissues. Revised 4th ed. Lyon: IARC, 2017: 44-50.

5. Wassie E, Finke C, Gangat N, Lasho TL, Pardanani A, Hanson CA, et al. A compendium of cytogenetic abnormalities in myelofibrosis: molecular and phenotypic correlates in 826 patients. Br J Haematol 2015;169:71-6.

6. Reilly JT. Cytogenetic and molecular genetic aspects of idiopathic myelofibrosis. Acta Haematol 2002;108:113-9.

7. Tefferi A, Mesa RA, Schroeder G, Hanson CA, Li CY, Deward GW. Cytogenetic findings and their clinical relevance in myelofibrosis with myeloid metaplasia. Br J Haematol 2001;113:763-71. 